Original article

\title{
A study of clinico-endoscopic profile of patient presenting with dyspepsia
}

\author{
Santosh B. Desai ${ }^{\mathrm{a}, *}$, Bhupendra N. Mahanta ${ }^{\mathrm{b}}$ \\ a Department of Internal Medicine, Jawharlal Nehru Medical College, Belgaum, Karnataka, India \\ ${ }^{\mathrm{b}}$ Department of Internal Medicine, Assam Medical College and Hospital, Dibrugarh, Assam, India
}

\section{A R T I C L E I N F O}

\section{Article history:}

Received 4 March 2017

Accepted 6 May 2017

Available online 12 May 2017

\section{Keywords:}

Dyspepsia

Endoscopy

Alarm symptoms

\begin{abstract}
A B S T R A C T
Introduction: Dyspepsia is a common clinical symptom with prevalence of 5-20\% of Outpatient (OPD) consultation at tertiary care hospital. The cause is not detectable in more than half of the patients. The common organic causes include peptic ulcer, esophagitis, and malignancy.

Aim: To study the clinical profile of patient presenting with dyspepsia in a tertiary care hospital of Assam, and correlate with endoscopic findings.

Materials: This is a hospital based observational study conducted over an year. Adult patient with dyspepsia was included after informed consent. Clinical data and endoscopic findings of patients with dyspepsia were collected with the help of a structured questionnaire.

Results: 158 patients with dyspepsia were assessed by Upper gastrointestinal (UGI) Endoscopy. Mean age of patient was $40.04 \pm 14.3$. 70.8\% patients were males. $15.19 \%$ had history of smoking, $50.06 \%$ had history of tobacco consumption, $38.61 \%$ were alcoholic and history of NSAID consumption was seen in $9.49 \%$. Alarm symptoms such as weight losss, anemia, UGI bleed were observed in $18.35 \%$ patients. Endoscopy revealed normal findings in $43.67 \%$ patients. Significant endoscopic findings were diagnosed in $56.32 \%$ patients. These included Peptic Ulcer in $25.95 \%$, esophagitis in $4.43 \%$, and UGI malignancy in $3.16 \%$. Other significant lesions constituted less than $2 \%$. Incidence of UGI malignancy was higher in patients more than 50 years. On comparing the endoscopic findings in patients of dyspepsia with alarm symptoms to those of dyspepsia without alarm symptoms, a statistical significance was observed with a $\mathrm{p}$ value of 0.013 .

Conclusion: In patients with dyspepsia presence of alarm symptoms is more significantly associated with organic lesion on endoscopy. Though the incidence of malignancy was low, endoscopy in patients more than 50 years may help in early diagnosis and reduced morbidity of these patients.
\end{abstract}

(c) 2017 Published by Elsevier, a division of RELX India, Pvt. Ltd on behalf of INDIACLEN.

\section{Introduction}

Dyspepsia is chronic or recurrent pain or discomfort centred in the upper abdomen.1 Dyspepsia is derived from the Greek words 'dys' and 'pepse' and literally means "difficult digestion."The Rome III criteria defined symptoms of dyspepsia as one or more of the following symptoms - Postprandial fullness, early satiety, epigastric pain or burning and no evidence of structural disease that is likely to explain the symptoms [Criteria fulfilled for the last 3 months with symptom onset at least 6 months prior to diagnosis].2,3

\footnotetext{
* Corresponding author at: Jawharlal Nehru Medical College, Belgaum, Karnataka, India.

E-mail addresses: santoshbdesai@gmail.com, santoshbdesai21@gmail.com (S.B. Desai).
}

Dyspepsia accounts for 4-5\% of general practitioner consultation and $20-40 \%$ of gastroenterological consultation.4 In studies of Asia, dyspepsia is more common in younger age group. A study from urban Mumbai, India found that dyspepsia was more prevalent in adults $>40$ years. 5 The data regarding clinical profile of dyspepsia in North east India where there is a significant consumption of tobacco and smoking is lacking.

Patients with 'alarm' symptoms,6 younger patients unresponsive to empirical treatment 6 and those over 55 years old with new onset dyspepsia, 6 require prompt investigation to exclude serious gastrointestinal disease. Alarm features include weight loss, anaemia, vomiting, haematemesis, malena and dysphasia. Endoscopy can help in early diagnosis and treatment of dyspepsia as well as early detection of malignancy in patients with dyspepsia and thus reducing the morbidity and a better outcome.

This study was intended with the following aim and objective: 
- To study the clinical profile of patient presenting with dyspepsia in a tertiary care hospital of Assam, and correlate with endoscopic findings.

- To determine whether alarm features are adequate to predict the need for endoscopy.

\section{Methodology}

The study was undertaken in Department of Medicine, Assam Medical College and Hospital, Dibrugarh during the period from July 2014 to June 2015. It is a Hospital based observational study. Patients of dyspepsia with or without alarm symptoms were screened. Out of the 426 patients, 158 were found eligible and gave consent to be included in the study. Upper Gastrointestinal (UGI) endoscopy was done in the 158 patients. Endoscopic biopsy and histopathological examination were performed in 8 patients with suspicion of malignancy.

\subsection{Inclusion criteria}

Patients age $>18$ years presenting with dyspeptic symptoms (for more than 3months with symptom onset more than 6 months before diagnosis) and with valid consent.

\subsection{Exclusion criteria}

Individuals who had known causes for dyspepsia and those patients who are unfit for endoscopy (shock, acute perforation, acute myocardial infarction, etc) were excluded.

\subsection{Statistical analysis}

Results were analysed using Graphpad software (c). Chi-square test, Fisher's exact test were used wherever applicable. Data were described in percentages, means, and standard deviations. A $\mathrm{p}$ value of less than 0.05 was considered significant.

\subsection{Primary outcome}

Organic lesions on endoscopy were found in $82.75 \%$ patients of dyspepsia with alarm symptoms in comparison to $50.38 \%$ in patients of dyspepsia without alarm symptoms.

\subsection{Secondary outcome}

A association of tobacco consumption with dyspepsia was observed with significant $\mathrm{p}$ value of 0.04 .

\section{Results}

Of the 158 patients included in the study 112 (70.8\%) were male and $46(29.2 \%)$ were female. Male to female ratio was 2.43: 1 [Fig. 1].

The most common age group in the study was found to be between $30-39$ years (30.38\%) followed by $20-29$ years $(22.15 \%)$. The minimum age was 18 years and maximum age was 81 years. Mean age of patient in our study group was $40.04 \pm 14.34$ years.

Symptom of early satiety was observed in 67 patients (42.41\%), epigastric pain in 114 patients (72.15\%), and postprandial fullness in 82 patients (51.90\%). The combination of early satiety, epigastric pain and postprandial fullness was seen in 20 patients (12.6\%), early satiety with epigastric pain was seen in 40 patients (25.31\%), epigastric pain with postprandial fullness in 44 (27.8\%) patients and early satiety with postprandial fullness in 41 patients (25.94\%). Only early satiety at presentation was seen in 6 patients $(3.80 \%)$, only epigastric pain and postprandial fullness was seen in 50 (31.64\%) and 17 (10.7\%) patients respectively.

In the study smoking was seen in 24 patients (15.19\%), tobacco consumption was seen in 80 patients (50.63\%), alcohol consumption in 61 patients (38.61\%), NSAID consumption in 15 patients $(9.49 \%)$ and herbal medication in 5 patient (3.16\%) [Table 1].

Out of 158 patients, Combination of alcohol, smoking and tobacco consumption was observed in 6 patients(3.79\%), combination of alcohol and tobacco consumption was observed in 28 patients(17.7\%), combination of smoking and tobacco consumption was observed in 4 patients(2.53\%), combination of smoking and alcohol in 6 patients (3.79\%).

Endoscopic finding was Normal in 69 patients (43.67\%), followed by Peptic Ulcer in 41 patients (25.92\%), Erosive gastroduodenitis in 37 patients (23.42\%), Oesophagitis in 7 patients (4.43\%), UGI Malignancy in 5 patients (3.16\%), oesophageal candidiasis in 2 patients (1.27\%). Other lesion included hiatus hernia, gastric polyp and Dieulafoy's lesion in 2 (1.27\%), 1(0.63\%) and $1(0.63 \%)$ patient respectively.

In the two groups, of patient of dyspepsia without alarm symptom and with alarm symptoms, benign lesion were found in 62 and 22 patients respectively, malignant lesions in 3 and 2 patients respectively. This was statistically significant with $\mathrm{p}$ value of 0.014 . On comparing the percentage distribution in patients of dyspepsia without alarm symptoms and dyspepsia with alarm symptoms: normal study (49.61\%) was most common finding in patients of dyspepsia without alarm symptom followed by erosive gastroduodenitis (24.80\%) followed by peptic ulcer (18.6\%) respectively. In patients of alarm symptom most common finding was peptic ulcer (58.6\%), followed by erosive and normal study (17.2\%) [Table 2] [Fig. 2].

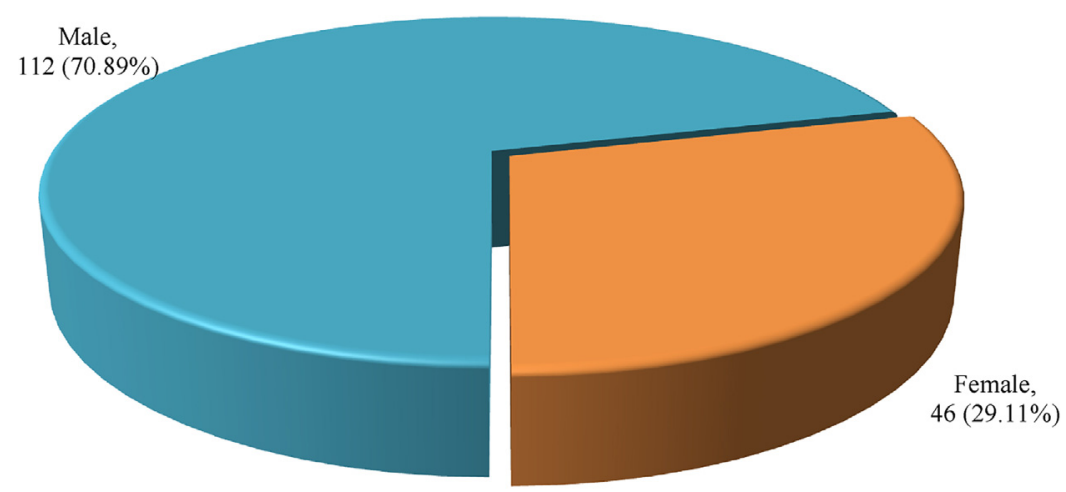

口Male $\square$ Female

Fig. 1. Sex Distribution. 
Table 1

Distribution of Risk Factors in Patient With Alarm and Without Alarm Symptoms.

\begin{tabular}{|c|c|c|c|}
\hline & Number (\%) With alarm $(n=29)$ & Number $(\%)$ Without Alarm $(\mathrm{n}=129)$ & $\begin{array}{l}p \text { value } \\
\text { (Fishers exact test) }\end{array}$ \\
\hline $\begin{array}{l}\text { Alcohol } \\
\text { Yes } \\
\text { No }\end{array}$ & $\begin{array}{l}18(62.06 \%) \\
11(37.93 \%)\end{array}$ & $\begin{array}{l}43(33.33 \%) \\
86(66.66 \%)\end{array}$ & 0.0078 \\
\hline $\begin{array}{l}\text { Smoking } \\
\text { Yes } \\
\text { No }\end{array}$ & $\begin{array}{l}2(6.89 \%) \\
27(93.10 \%)\end{array}$ & $\begin{array}{l}22(17.05 \%) \\
107(82.9 \%)\end{array}$ & 0.258 \\
\hline $\begin{array}{l}\text { Tobacco } \\
\text { Yes } \\
\text { No }\end{array}$ & $\begin{array}{l}20(68.96 \%) \\
9(31.03 \%)\end{array}$ & $\begin{array}{l}60(46.51 \%) \\
69(53.48 \%)\end{array}$ & 0.0477 \\
\hline $\begin{array}{l}\text { NSAIDs } \\
\text { Yes } \\
\text { No }\end{array}$ & $\begin{array}{l}2(6.89 \%) \\
27(93.10 \%)\end{array}$ & $\begin{array}{l}13(10.07 \%) \\
116(89.92 \%)\end{array}$ & 0.8591 \\
\hline
\end{tabular}

In age group of $>50$ years, UGI malignancy was seen in $12.12 \%$ and in $<50$ years was seen in $0.8 \%$. The result was statistically significant $(\mathrm{p}=0.01)$ [Table 3 ].

When dyspepsia was associated with alarm symptoms the likelihood of getting more abnormality on endoscopy was high [Table 4], which was statistically significant ( $\mathrm{p}$ value $=0.013$ ).

\section{Discussion}

In our study male to female ratio was 2.43:1. Gado A et al.7 reported a incidence $51 \%$ in males and $49 \%$ in females. Thomson $A$. B.R et al.8 reported a male to female ratio of $1: 1$. In India Sumathi B et al.9 reported a male to female ratio of $1.5: 1$ and Sunil Kumar et al.10 reported a ratio of 1.05:1.

Our observation shows a male preponderance most probably attributed to the increased consumption of alcohol, smoking and tobacco which play a key role in pathogenesis of dyspepsia. It may also be attributed to the fact that in our society women's health problems are not given priority and fewer symptomatic women than men present to health facilities.

Gado A et al.7 reported 450 (32.14\%), 22 (1.57\%), 388 (27.71\%) patients who had history of smoking, alcohol consumption and NSAID ingestion respectively. The difference was statistically significant in patients who smoked and consumed alcohol but not in patients who only consumed alcohol. Sumathi et al.9

Table 2

Comparison of Endoscopic Findings in Patient of Dyspepsia With Alarm and Without Alarm Symptoms.

\begin{tabular}{|c|c|c|c|c|c|}
\hline \multirow[t]{2}{*}{ Endoscopic Findings } & \multicolumn{2}{|c|}{ Dyspepsai Without Alarm Symptoms } & \multicolumn{2}{|c|}{ Dyspepsia With Alarm Symptoms } & \multirow[t]{2}{*}{$\mathrm{p}$ value (Fishers exact test) } \\
\hline & $\mathrm{n}=129$ & $\%$ & $\mathrm{n}=29$ & $\%$ & \\
\hline Normal Study & 64 & 49.61 & 5 & 17.20 & 0.0016 \\
\hline Erosive Gastroduodenitis & 32 & 24.80 & 5 & 17.20 & 0.4727 \\
\hline Peptic Ulcer & 24 & 18.60 & 17 & 58.60 & $<0.0001$ \\
\hline Oesophagitis & 6 & 4.60 & 1 & 3.40 & 1.0000 \\
\hline UGI Malignancy & 3 & 2.30 & 2 & 6.80 & 0.2485 \\
\hline Oesophageal Candidiasis & 1 & 0.77 & 1 & 3.40 & 0.334 \\
\hline Others & 4 & 3.10 & 0 & 0.00 & - \\
\hline TOTAL & 129 & 100.00 & 29 & 100.00 & \\
\hline
\end{tabular}

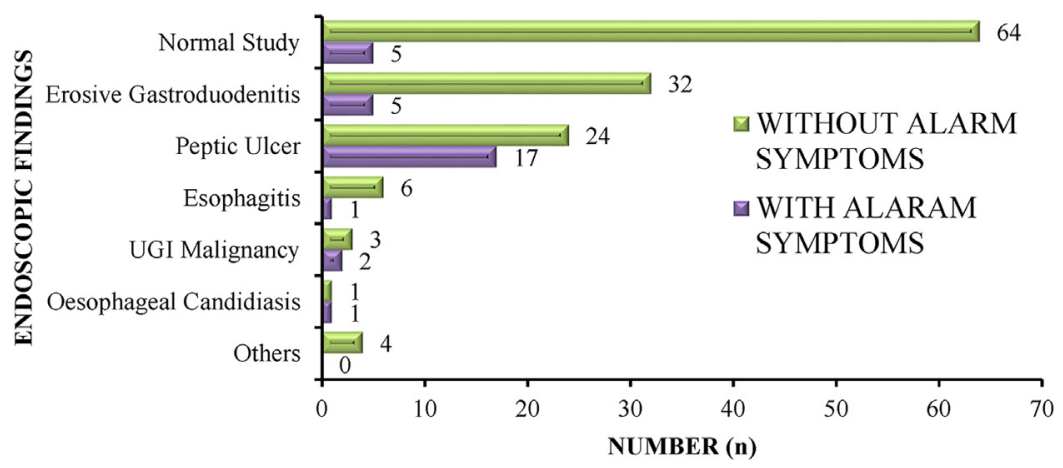

Fig. 2. Comparison of Endoscopic Findings in Patient of Dyspepsia with Alarm and Without Alarm Symptoms. 
Table 3

Incidence of UGI Malignancy in Relation to Age Group.

\begin{tabular}{|c|c|c|c|c|c|}
\hline \multirow[t]{2}{*}{ UGI Malignancy } & \multicolumn{2}{|c|}{$\leq 50$ Years } & \multicolumn{2}{|c|}{$>50$ Years } & \multirow[t]{2}{*}{$p$ value } \\
\hline & $\mathrm{n}=125$ & $\%$ & $\mathrm{n}=33$ & $\%$ & \\
\hline Present & 1 & 0.8 & 4 & 12.12 & 0.0070 \\
\hline Absent & 124 & 99.2 & 29 & 87.87 & \\
\hline
\end{tabular}

reported Alcohol consumption, smoking, and NSAID use in 80 (2.9\%), 259 (9.4\%), 150 (5.4\%) respectively in patients with alarm symptoms and $21(3.1 \%), 68(10.2 \%), 26$ (3.9\%) respectively in patient without alarm symptoms.

However in our study dyspepsia was significantly associated with alcohol and tobacco consumption. However the association was not significant in patients with NSAID intake and smokers. This discrepancy may be due to the wide social difference and dietary habits. It may also be due to the inherent alcohol drinking and tobacco consumption habits in this region, 12 genetic composition and the life style of this region. This may also be a beta error attributed to the small sample size of the study.

Sumathi B et al.9 reported a normal study in 1453 patients (42.3\%), and $44.3 \%$ in patients with dyspepsia without alarm symptoms and $34.7 \%$ in patients with dyspepsia with alarm symptom. Gado A et al.7 reported normal findings in 65\% patients presenting with dyspepsia and $82 \%$ of patients younger than 30years. Manes et al.11 reported a total of 168 patients with appropriate upper gastrointestinal endoscopy to have normal endoscopic findings. Our study is almost in concordance with other studies. The slight variation in the study may be due to the geographical and social differences and short duration of study.

In our study the results also showed that epigastric pain was the most common presentation of patients. Among the benign lesions, most common was peptic ulcer disease $(25.95 \%)$ followed by erosive gastroduodenitis (23.42\%). Also peptic ulcer disease was more common in patients with alarm symptoms. Manes et al.,11 Sumathi et al.,9 Sunil Kumar et al.10 reported duodenal ulcer in $31.01 \%, 10.9 \%, 18.6 \%$ respectively and gastric ulcer in $6.37 \%, 5.3 \%$, $6.1 \%$ respectively. Our study showed duodenal ulcer in $21.5 \%$, gastric ulcer in $4.43 \%$ respectively.

The higher percentage of peptic ulcer disease among the alarm group may be due to obvious alarm symptoms like haematemesis and melaena, hence immediate presentation of the patients to the hospital.

In our study we found 7 patients (4.43\%) to have Oesophagitis. Out of the 7 Patients, 1 had dyspepsia with alarm symptom and 6 had dyspepsia without alarm symptomAmong the 7 patients, 3 (42.86\%) were classified as Los Angeles grade A and 4 (57.14\%) were classified as Los Angeles grade B. Manes et al.,11 Gado et al.,7 Sunil Kumar et al.,10 reported Oesophagitis in 11.6\%, 0-23.0\%, 15.6\% respectively.

The discrepancy in the studies can be attributed to the significant overlap of the symptoms of Dyspepsia and Gastrooesophageal reflux disease leading to a selection bias of sample and the lack of proper defining landmark for differentiating heartburn and epigastric pain or burning.
In the present study, we observed UGI Malignancy in 5 (3.16\%) patients of dyspepsia. Among the 129 patients of dyspepsia without alarm symptoms $3(2.3 \%)$ were diagnosed to have UGI malignancy and among the 29 patients of dyspepsia with alarm symptoms $2(6.8 \%)$ were diagnosed to be UGI malignancy. Malignant lesions were diagnosed in patients of duration of more than 6 months.

Gado A et al.7 reported 16 (1\%) patients with UGI malignancy among patients with dyspepsia. Ages ranged from 37 to 75 years. UGI malignancy was diagnosed in $1 \%$ of patients aged $30-50$ years and $2 \%$ of patients more than 50 years $(\mathrm{P}=0.003)$. UGI malignancy was not found in dyspeptic patients younger than 30 years old. Sumathi B et al.9 reported a total of 282 patients (8.27\%) of UGI malignancy, among these 125 (4.5\%) were reported in patients of dyspepsia without alarm symptoms and 48 (21.6\%) were reported in patients of dyspepsia with alarm symptoms. Sunil Kumar et al.10 reported gastric cancer in $2.8 \%$ patients and Manes et al.11 reported $6(0.86 \%)$ patients of gastric cancer out of 706 patients studied. Thomson A.B.R et al.8 reported malignancy in less than $2 \%$ of the patients.

The results in our study may be attributed to the inherent geographical variation, unusual clustering of cases at the tertiary care hospital, short duration of the study and unknown etiological factors like genetic and dietary differences as well as the small sample size of the study.

In addition, white light endoscopy was used during the study. Use of narrow band imaging or other chromoendoscopic techniques may help in early detection of malignant lesions and thereby early intervention may be possible.

In the present study biopsy was done in 8 patients with suspicious lesions to confirm the endoscopic findings. Out of the 8 patients with suspicious lesions, 2 were found to have gastric ulcer, low grade dysplasia in 1 patient, squamous cell carcinoma of oesophagus was found in 2 patients, adenocarcinoma of oesophagus in 2 patient and adenocarcinoma of stomach in 1 patient.

The age group of the patient with UGI malignancy was between $45-65$ years. The mean age was $56.7+7.8$. UGI malignancy increased in age group more than 50 years. The p value was statistically significant $(\mathrm{p}=0.0070)$ for UGI malignancy in 2 groups, age group $\leq 50$ years and $>50$ years.

\section{Conclusion}

Dyspepsia is a relatively common entity in day to day practice.

The presence of alarm symptom is statistically associated with more organic lesions on endoscopy.

Dyspepsia in age above 50 years is commonly associated with underlying organic lesions or malignancy.

UGI endoscopy is simple procedure that can be undertaken for early diagnosis of benign as well as malignant lesions in patient presenting with dyspepsia.

\section{Conflict of interest}

The authors have none to declare.

Table 4

Outcome of Endoscopy in Patient of Dyspepsia With and Without Alarm Symptoms.

\begin{tabular}{|c|c|c|c|c|c|}
\hline \multirow[t]{2}{*}{ groups } & \multicolumn{3}{|c|}{ Endoscopic Findings } & \multirow[t]{2}{*}{ Total } & \multirow[t]{2}{*}{$p$ value } \\
\hline & Normal Study & Benign Lesions & Malignant Lesions & & \\
\hline Dyspepsia without Alarm symptoms & 64 & 62 & 3 & 129 & 0.01357 \\
\hline Dyspepsia with Alarm Symptoms & 5 & 22 & 2 & 29 & \\
\hline
\end{tabular}




\section{Ethical clearance}

Taken From Institutonal Ethics Committee (IEC), Assam Medical college, Dibrugarh.

\section{References}

1. Akhta A, Shheen M. Dyspepsia in African and American and hispani patient. $J$ Natl Med Assoc. 2004;0(96):635-640.

2. Khan N, Shabbir G, Zarif M, Khattak. Upper Gastrointestinal endoscopic assessment of Patients presenting with dyspepsia. JPMI. 2007;21:209-216.

3. Pare P. Systematic approach toward clinical diagnosis of functional dyspepsia. Can J Gastroenterol. 1999;13:647-654.

4. Locke GR. Nonulcer dyspepsia: what it is and what it is not. Mayo Clin Proc. 1999; 74:1011-1015.

5. Shah SS, Bhatia SJ, Mistry FP. Epidemiology of dyspepsia in the general population in Mumbai. Indian J Gastroenterol. 2001;20:103-106.

6. Davidson's Principle and practice of medicine. Alimentary tract and pancreatic disease. Presenting problem in gastrointestinal disease. Dyspepsia. 20th edition :864-866.
7. Gado A, Ebeid B, Abdelmohsen A, et al. Endoscopic evaluation of patients with dyspepsia in a secondary referral hospital in Egypt. Alex J Med. 2015;51(3):17918410.1016/j.ajme.2013.10.001.

8. Thomson ABR, Barkun AN, Armstrong D, Chiba N, Whites RJ, Daniels S. The prevalence of clinically significant endoscopic findings in primary care patients with uninvestigated dyspepsia: the Canadian Adult dyspepsia Empiric Treatment-Prompt Endoscopy (CADET-PE) study. Aliment Pharmacol Ther. 2003; 17:1481-1491.

9. Sumathi B, Navaneethan U, Jayanti N. Appropriateness of indications for diagnostic upper GI endoscopy in India. Singap Med J. 2008;49(12):970.

10. Kumar Dr Sunil, Pandey Dr Hari Ignatius, Verma Dr Arunima, Deb Dr Partha Pratim. Prospective analysis of 500 cases of upper gi endoscopy at Tata Main Hospital. IOSR J Dent Med Sci (IOSR-JDMS). 2014; 13(January (1 Ver. III))21-25 eISSN: 2279-0853, p-ISSN: 2279-0861.

11. Manes G, Balzano A, Marone P, Lioniello M, Mosca S. Appropriateness \& diagnostic yield of upper GI endoscopy in an open access endoscopy system: a prospective observational study based on the Maastricht Guidelines. Aliment Pharmacol Ther. 2002;16:105-110.

12. Medhi GK, Hazarika NC, Mahanta J. Tobacco and alcohol use among the youth of agricultural tea industry in Assam. Southeast Asian J Trop Med Public Health. 2006 May;37(3):581-586. 